\title{
Epidemiology of spinal injuries in Romania
}

\author{
A Soopramanien MD $\mathrm{PhD}$ \\ Senior Registrar in Spinal Injuries, Royal National Orthopaedic Hospital, Brockley Hill, \\ Stanmore, Middlesex, England
}

\begin{abstract}
Retrospective and prospective epidemiological studies in Bucharest indicated a high rate of spinal injuries (about 28.5 per million population per year) in Romania. Most patients were poor, male, manual workers. Half of them were aged less than 40. Falls, particularly from horse-drawn carts, and road traffic accidents were the most frequent causes of injury. In summer, diving accidents were a common cause of spinal injuries. Sixty per cent of the patients had cervical injuries. Pressure sores became less frequent as staff and relatives were trained to turn and position patients. Because gastroduodenal bleeding and deep vein thrombosis were rare, the systematic use of drugs to prevent these conditions was deemed to be unnecessary, given the financial constraints. A shortage of beds and facilities made it difficult to manage associated injuries in a neurosurgical clinic in Bucharest or to admit all patients for rehabilitation. Thirty-nine per cent of all patients admitted with spinal injuries had spinal surgery ( $61 \%$ of those with neurological impairment). Bone grafting was the most common procedure for cervical injuries; surgical stabilisation was not commonly performed due to the shortage of plates and screws. The mortality rate in the early days post injury decreased from $22 \%(1985-1991)$ to $10.1 \%$ (1992) as medical management improved and the relatives helped with care in the acute phase. A programme is needed in Romania to prevent the accidents that cause spinal injuries and to improve clinical management. As a result of this study, three films were made to aid the prevention of accidents and to train staff and relatives in the care of those with spinal cord injuries.
\end{abstract}

Keywords: spinal injuries; spinal cord injuries; epidemiology; Romania; management; complications.

\section{Introduction}

The International Red Cross and Red Crescent Movement were quick to respond to the human consequences of the political events which occurred in Romania in December 1989. Within hours of fighting breaking out, a team of medical and other personnel were despatched to Bucharest to assist the wounded and victims of the conflict. After the worst fighting was over, the International Committee of Red Cross (ICRC) asked me to go to Romania to organise the local care and management of those who had sustained spinal injuries. However, the government authorities ac- cepted the offer from many countries to fly the wounded with spinal cord injuries out of the country for specialised treatment abroad, and quite quickly they all left Romania.

As people with spinal cord injuries need a life-time medical follow up, it was thought wise to organise rehabilitation services for patients returning from abroad. In addition, an initial country-wide survey which the ICRC carried out had highlighted the pressing needs of all physically disabled people in Romania. However, donor societies and countries seemed reluctant to consider those with physical disabilities when the media 
were focusing on the miseries of children in orphanages. Probably because funds were limited, the International Federation of Red Cross and Red Crescent Societies (which coordinated Red Cross activities after the acute phase) did not expand the project to include other disabilities. They chose to concentrate on an area-spinal cord injuries - in which the Red Cross movement had become expert.

The spinal injury project which I headed, began in July 1991. My priority was to reorganise the clinical services so that new techniques, methods of treatment and drugs could be introduced. Epidemiological studies were needed to assess the medical and social requirements of those with spinal cord injuries. When means are limited, it is especially important that they are applied to best effect. Epidemiological studies assist with this and help to justify additional assistance from the international community.

\section{Methods}

I based the clinico-pathological database for traumatic spinal injuries on the experience gathered in an earlier study in Peshawar (Pakistan) where the ICRC initiated a spinal injury project. The database concentrated on the number of spinal injuries, extent of physical damage, medical complications, and cause of injuries and was used to audit the funds donated.

Medico-social surveys analyse the level of injury in relation to age, profession, income, social problems, architectural barriers and social support so that help can be offered to patients in their homes.

The Romanian project was primarily designed to improve the comprehensive management of spinal cord injuries in an existing hospital in Bucharest. The $\mathrm{Dr}$ Gh. Marinescu Hospital was opened in 1935 and its director, Pr A. Constantinovici, believes that it treats the greatest number of neurological injuries in Europe. All types of neurosurgical disease are treated at the hospital, and since 1975 it has also provided rehabilitation facilities under the leadership of Dr I. Tudor. The surveys focused on the treatment of patients with spinal injuries at this clinic.

(1) Retrospective analysis. The files of all 6000 patients admitted from 1975 to December 1991 were analysed (notes and X-rays). Though in certain areas such as neurological definitions they might not have been totally accurate, the information that they provided was invaluable.

(2) Prospective study of activity from January 1992 to January 1993. The data were collected daily for 412 patients. They confirmed the general trends shown by the retrospective studies and were more precise.

The information gathered was processed by computer. Ideally similar studies should have been done in other big cities in Romania. This was beyond the scope of the project. None the less, it is important to know the incidence of spinal injuries in Romania. This can be calculated from the number of patients admitted, their geographical distribution, the catchment area of the clinic, and the role and importance of other neurological clinics in Romania.

\section{Results}

\section{Incidence of spinal injuries}

Each year about 400 Romanians with spinal injuries were admitted; typically about 270 had cord involvement (Fig 1). Of the 412 admitted in 1992, 262 had neurological damage. The patients mainly came from in and around Bucharest and the lower half of the country, an area where about $40 \%$ of the population lives. By extrapolation to the 23 million inhabitants of Romania, this represents at least 28.5 spinal cord injuries per million inhabitants. Many died at the site of the accident; others were treated in general hospitals. (Many files of 1991 were missing in the Medical Records Department: this accounts for the low figures for 1991).

\section{Sex, age, occupation}

The ratio between male and female was 3.35:1 and there were as many people under 


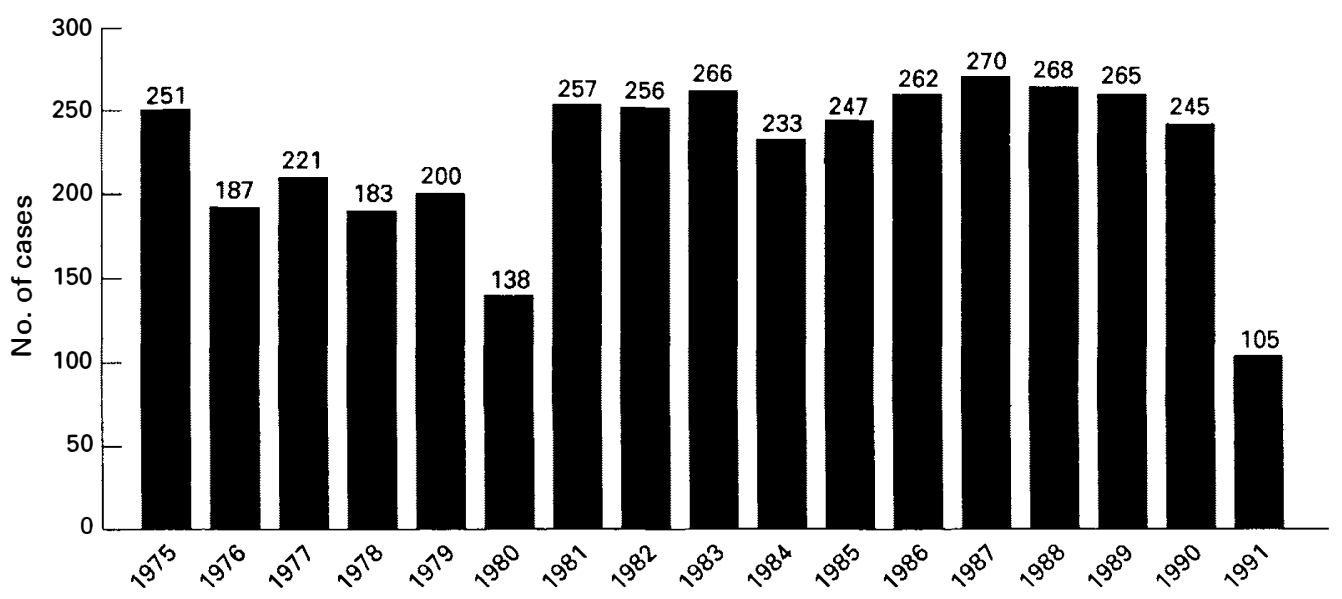

Figure 1 Distribution of admissions per year (spinal cord injured patients 1975-1991)

40 as above this age (Fig 2). Forty per cent of the patients were manual workers, $12 \%$ were intellectuals and $18 \%$ were retired (Fig $3)$. Most patients were poor.

\section{Causes of injury}

Falls from heights, especially from horsedrawn carts, caused $59 \%$ of the injuries and road traffic accidents $13 \%$. Diving accidents in the summer accounted for $7 \%$ of injuries (Table I).

\section{Time between injury and admission}

Forty-five per cent of patients were admitted within a day of injury, $31 \%$ within the first week and $10 \%$ between week one and two. By that time pressure sores had developed in 26 patients ( $44 \%$ of all sores). This emphasises the importance of early transfer to a specialised unit.

\section{Neurological level}

Cervical injuries accounted for $60 \%$ of neurological deficits (Fig 4). Forty-seven

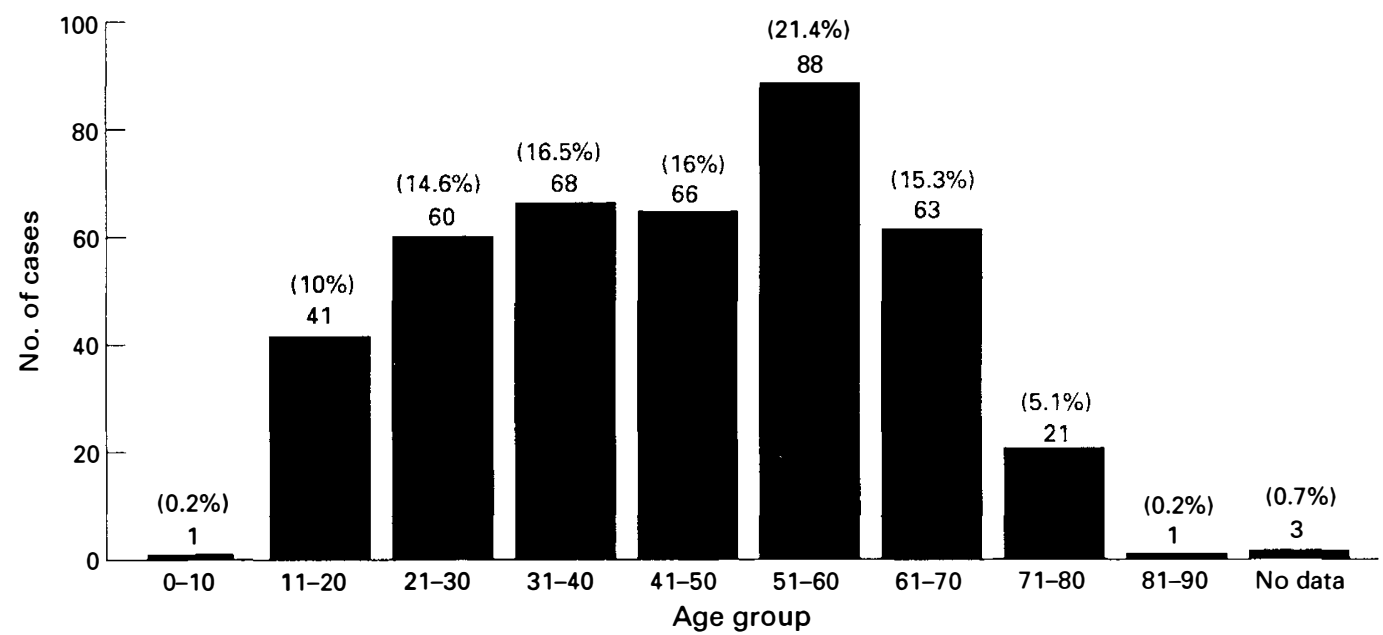

Figure 2 Distribution of age groups at time of injury (new patients 01/01/92-01/01/93) 


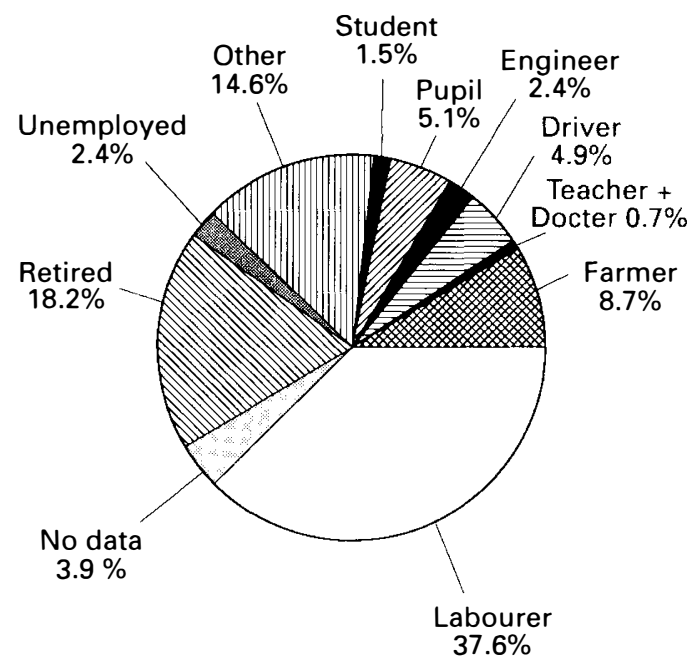

Figure 3 Distribution by occupation (new patients $01 / 01 / 92-01 / 01 / 93$ )

Table I Causes of injury (new patients 1.1.92-1.1.93)

\begin{tabular}{lcc}
\hline Causes of injury & $\begin{array}{c}\text { No. of } \\
\text { cases }\end{array}$ & $\begin{array}{c}\% \text { Of } \\
\text { injuries }\end{array}$ \\
\hline Fall from height & 165 & 40 \\
Fall from cart & 77 & 19 \\
Road traffic accident & 54 & 13 \\
Weight fallen on patient & 40 & 10 \\
Diving accident & 29 & 7 \\
Other cart accident & 12 & 3 \\
Other causes & 35 & 8 \\
\hline
\end{tabular}

per cent of them were incomplete lesions. Table II shows the Frankel classification of neurological status at admission and at discharge from hospital. A indicates complete spinal injury and $\mathrm{B}, \mathrm{C}, \mathrm{D}$ represent incomplete lesions. $\mathrm{E}$ is the normal state.

Thirty-six patients showed some degree of recovery (Table II). Of the patients with incomplete lesions $46 \%$ had a central cord and $4 \%$ had a Brown Séquard syndrome (Fig 5).

\section{Medical complications}

In 55 patients (that is $21 \%$ of those with a spinal cord injury) a pressure sore developed: in addition to the 26 mentioned above, 29 others contracted a sore in the hospital (mainly in the first 3 months of

Table II Frankel classification of neurological status at admission and discharge from hospital

\begin{tabular}{lrrrrr}
\hline & \multicolumn{5}{c}{ Discharge } \\
\cline { 2 - 6 } & A & B & C & D & E \\
\hline Admission & & & & & \\
A & 122 & 6 & 6 & 0 & 0 \\
B & 0 & 17 & 1 & 6 & 0 \\
C & 0 & 1 & 14 & 10 & 0 \\
D & 0 & 0 & 0 & 66 & 7 \\
E & 0 & 0 & 0 & 0 & 150 \\
\hline
\end{tabular}

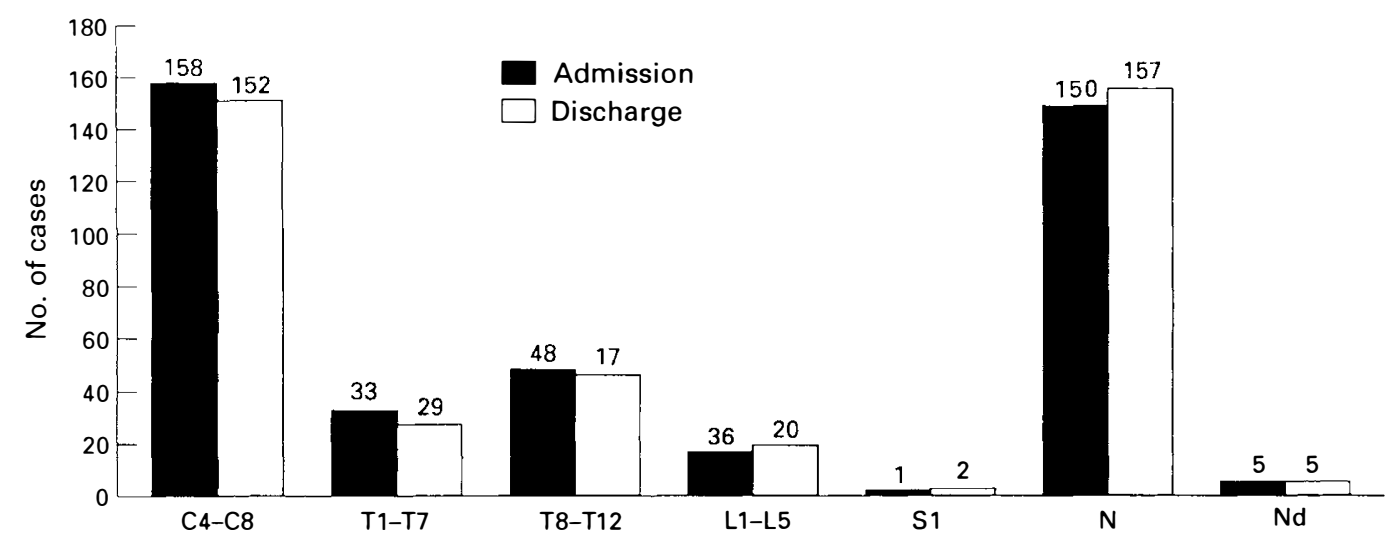

Figure 4 Neurological levels (new patients 01/01/92-01/01/93). C - Cervical; $\mathrm{T}$ - Thoracic; L - Lumber; S - Sacral; N - Normal; Nd - No data 


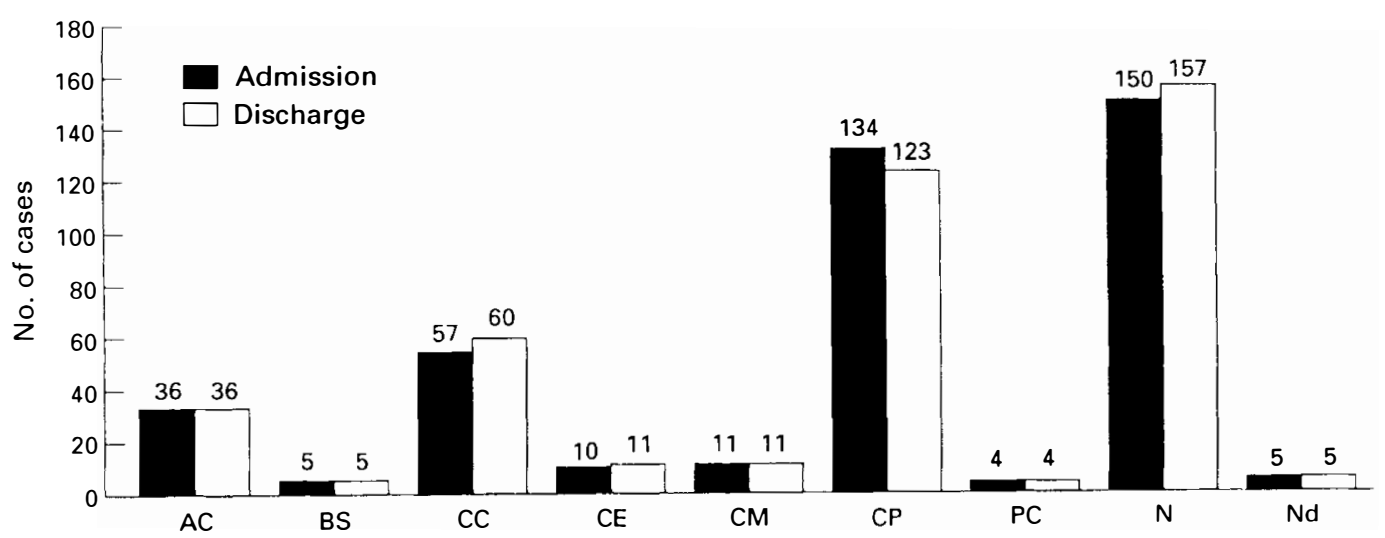

Figure 5 Clinical syndromes (new patients 01/01/92-01/01/93) AC - Anterior cord; BS - Brown Séquard; CC - Central cord; CE - Cauda equina; CM - Conus medullaris; CP - Complete; PC - Posterior cord; N - Normal; Nd - No data

1992). Once the members of the project started to supervise the turning and positioning of patients, pressure sores became rare except in patients who were not admitted quickly to the unit, and had developed pressure sores in district hospitals and at home.

Patients in the neurosurgical wards generally had an indwelling urinary catheter; intermittent catheterisation was generally used in those in the rehabilitation ward. Over $71 \%$ of rehabilitation patients had urinary tract infections. Two patients had epididymo-orchitis and eight others had haematuria.

Other complications included deep vein thrombosis (10 women and 11 men), seen mainly in the summer months; digestive disorders such as diarrhoea (40 cases) and constipation (75 cases); and respiratory problems in 40 patients, of whom 13 died. There was only one case of gastric dilatation and gastroduodenal bleeding and six cases of paralytic ileus.

\section{Associated injuries}

Over $24 \%$ of the patients had associated injuries, mainly head injuries $(41 \%$ of associated injuries) and upper limb fractures $(23 \%)$. There were injuries to the lower limb, thorax, and abdomen in 18\%, $11 \%$ and $2 \%$ respectively.

\section{Length of stay}

The 412 patients were initially admitted to the intensive therapy unit before being transferred to surgery. The 157 patients without spinal cord involvement, were discharged home from the surgical ward after surgery and/or bracing. Only 120 of the 262 with neurological impairment could be admitted to the rehabilitation ward. Patients were therefore kept longer in the surgical ward, where they had basic rehabilitation before being discharged to district hospitals or home. Another problem was the limited number of specialised spinal surgeons in Romania: this resulted in long waiting lists for surgery. Over $24 \%$ were operated on between 1 and 2 months after being injured; $30 \%$ had surgery during the first week. Previously, patients had 6 weeks' bed rest even if they had undergone surgical stabilisation. However, once we had set up an orthopaedic workshop to design and make cervical collars and thoraco-lumbar braces, we were able to mobilise patients earlier.

\section{Type of surgery}

Thirty-nine per cent of all patients admitted were operated on $(61 \%$ of those with neurological impairment). The techniques used included laminectomy (6.9\% of cases), bone grafting $(38.2 \%)$, wiring and disc 
ablation. Only $3.7 \%$ had plates and screws due to the absence of these materials on the local market.

\section{Mortality rate}

The mortality rate in the early days post injury fell from $22 \%$ (retrospective studies) to $10.1 \%$ (prospective studies) as a result of better management of pulmonary complications, improved urinary care and the introduction of total initial care from the admission of the patient. An important element was the involvement of relatives in turning and positioning patients as well as in chest physiotherapy. Eighty-six per cent of those who died had cervical injuries.

\section{Level of staffing}

There was one medical doctor (physician and/or surgeon) and one trained nurse for 14 patients. The four 'physiotherapists' on the unit performed well although they had no formal training in physiotherapy. In Romania physiotherapists are generally recruited from a pool of physical training teachers having been given 1 year of additional paramedical training in basic medical sciences. There was a ratio of one physiotherapist to 20 patients. Our team trained two 'occupational therapists' on the job: occupational therapy was a new concept in Romania. They dealt with hand function, functional rehabilitation and participated in home visits. Social workers had not been trained in Romania since 1979. The only psychologist in the unit worked mainly in the psychiatric clinic and could spend little time with patients with spinal injuries.

\section{Discussion}

The incidence of spinal cord injuries was estimated to be 28.5 per million inhabitants. This figure is based solely on the patients who were admitted to the Dr Gh. Marinescu Hospital. It does not include those admitted to district general hospitals (and not referred to the neurosurgical clinic) and those who died at the site of the accident or while being transported to the hospital. In these cases the cause of death was often unknown because there were no organised first-aid or rescue services in Romania, and patients were often managed by nonprofessionals at the site of the accident. The incidence of spinal injuries in Romania resembles those in the Federal Republic of Germany (36.0) $(1983)^{1}$ and Japan (39.4 per million) (1990). ${ }^{2}$ The incidence in Denmark is much lower (9.2 per million) (1975-84). ${ }^{3}$ It would have been interesting to compare the Romanian situation with that prevailing in other Eastern and developing countries. Unfortunately the international agencies which I contacted in October 1993, could not provide any such data.

Reports from Nigeria $(1980-85)^{4}$ and India ${ }^{5}$ show that 'falls from a height' are the main cause of spinal injuries in these countries too. In Romania, falls from trees are common in spring and autumn: Okonkwo explains that in Nigeria, there is a weakening of the tensile strength of jigs from November to March. In rural India, falls from trees were responsible for $55.2 \%$ of all spinal cord injuries. There is a striking similarity between Romania and Poland $(1965-91)^{6}$ in the number of falls from horse-driven carts, and injuries caused by diving into shallow water in summer. In developed countries motor vehicle accidents are the chief cause of spinal cord injuries. In Romania such accidents caused $27.2 \%$ of spinal injuries.

Many of the Romanian patients (40\%) were more than 50 years old: a high proportion of those who fell from a height were elderly. The sex ratio of males/females was $3.35: 1$. This compares with $3.45: 1$ in Cana$\mathrm{da}^{7}$ and 3.3:1 in Denmark. ${ }^{3}$ Most of the accidents happened in rural areas where most people were either labourers or farmers. Most of those injured had limited financial means, even if they were professionals.

I believe that the incidence of spinal cord injury could be reduced by an intensive campaign to prevent falls, cart accidents and diving accidents. Most patients with spinal cord injuries were male breadwinners, supporting families. They received little financial support from official sources after the accident.

The general public should be taught how to handle patients at the scene of the 
accident to avoid further damage to the spine. They should also be told that early admission to a specialised unit is vital. There, specialised teams can manage the bony and neurological lesion and determine rehabilitation goals. The high proportion of cervical injuries, incomplete lesions and central cord sydromes make it essential to have expert teams. Occupational therapists, physiotherapists and rehabilitation doctors should manage the patients in a coordinated manner.

The data helped us convince decision makers of the needs for more beds, staff and support. A few posts were created. None the less, a lack of government funds led to inadequate staffing levels. The team members of the project offered specialised training to the available staff. The medical and the nursing staff were assisted by the patients' carers, who also needed training. In developing countries or in those facing economic difficulties, the family could compensate for the lack of trained staff where it is too expensive for staff to cover the patient's 24 hour needs.

Our team made two films to train staff and carers. Those caring for patients with spinal injuries should be shown how to turn and position patients to avoid pressure sores. The urinary tract must be kept free from infection to preserve the kidneys. The use of intermittent catheterisation, which was widespread in the rehabilitation ward, was gradually being introduced in the surgical wards. It may not be necessary to follow blindly the protocols of prevention and treatment often used in developed countries. For example the incidence of deep vein thrombosis (DVT) or pulmonary embolism (PE) may not be high enough to justify the systematic use of anticoagulants to prevent this condition. Perhaps only clinically diagnosed DVTs should be treated, given the financial constraints. I do not underestimate the importance of DVT or PE, and the phenomenon of hypercoagulability but we must advocate a practical approach based on financial realities to ensure the long-term survival of the project. The same argument applies to gastro-duodenal bleeding, in the context of countries experiencing financial difficulties.
Much stress was laid on clinical surveillance of the patients by low-cost means. Nurses were encouraged to record the temperature regularly on the grounds that 'fever may be the earliest and possibly the only clinical sign of otherwise occult thromboembolic disease'. ${ }^{8}$ They also recorded the size of thigh and calf in the acute stage. Passive mobilisation was carried out as early as possible after injury. Many Romanians were very heavy smokers, and pulmorespiratory problems were common. If, as Reines and Harris claim ${ }^{9}$ 'rotating beds may minimise the pulmonary complications' these could be introduced in addition to the chest physiotherapy. Such beds could be manually or mechanically operated: they do not have to be electronic. Our team worked on prototypes for manual beds.

The management of associated injuries was not always satisfactory as there were no X-ray facilities at the week-end, but the transformation of the clinic into an emergency hospital in January 1994, is a step in the right direction. It now has traumatology, cardiology and radiology facilities. Other problems that will have to be solved are the training and availability of more spinal surgeons, physicians, paramedicals, beds for rehabilitation and equipment.

We recognise that more patients will be attracted to Bucharest where facilities and training have been improved, but the many other neurosurgical centres within the country should have similar facilities. Our idea was therefore to develop a 'model' in Bucharest, and spread it to other parts of the country. The Spinal Injury Conference organised by the Romanian Society of Neurosurgery (May 1993) gave us the opportunity of disseminating our findings and attempting to design a spinal health planning programme for the country. The studies also drew attention to the urgent need for an accident prevention programme. As a result, a 10-minute film was made by the Red Cross team and its Romanian partners, and shown on National Romanian Television in January 1993. It focused on the need to prevent falls and gave advice on taking precautions before diving.

The present paper will be followed by a 
medico-social survey in a bid to get more help from the international community to improve the social integration of these patients. The Romanians have taken the initiative and established a Foundation of Spinal Trauma. They deserve to be encouraged and supported with equipment (surgical and medical), medicaments, and scientific exchanges.

Too often rehabilitation medicine in the developing world is seen as a luxury. It attracts little attention despite reports from United Nations sources that $10 \%$ of the world population is disabled. Further, the incidence of spinal injuries is often under- estimated and the cost of their management is thought to be higher than it is.

\section{Acknowledgements}

My thanks go to Dr H L Frankel and Mr I Nuseibeh (Stoke Mandeville), Mr D Grundy (Salisbury), Pr Constantinovici, Dr Panoza, Dr Exergian, Dr Tudor (Romania) for their friendship, help and support; to the members of the Spinal Injury Project who participated in this study, and in particular to $\mathrm{Mr}$ A Popescu and Mrs L Minoui (Computer Specialists).

The Spinal Injury Project was funded by the International Federation of Red Cross and Red Crescent Societies.

\section{References}

1 Koning W, Frowein RA (1989) Incidence of spinal cord injury in the Federal Republic of Germany. Neurosurg Rev 12: 562-566.

2 Shingu H, Ikata T, Katoh S, Akatsu T (1994) Spinal cord injuries in Japan: a nationwide epidemiological survey in 1990. Paraplegia 32: 3-8.

3 Biering-Sorensen E, Pedersen V, Clausen S (1990) Epidemiology of spinal cord lesions in Denmark. Paraplegia 28: 105-118.

4 Okonkwo CA (1988) Spinal cord injuries in Enugu, Nigeria-preventable accidents. Paraplegia 21: 12-18.

5 Chacko V, Joseph B, Mohanty SP, Jacob T (1986) Management of spinal cord injury in a general hospital in rural India. Paraplegia 24: 330-335.

6 Kiwerski SE (1993) The causes, sequelae, and attempts at prevention of cervical spine injuries in Poland. Paraplegia 31: 527-533.

7 Canadian Paraplegic Association. Annual Reports on Spinal Cord Injuries. Ontario 1991, 1992, 1993.

8 Weingarden SI, Weingarden DS, Belen J (1988) Fever and thromboembolic disease in acute spinal cord injury. Paraplegia 26: 35-42.

9 Reines HE, Harris RC (1987) Pulmonary complications of acute spinal cord injuries. Neurosurgery 21: 193-196. 